\title{
Clinical profile of patients with pleural effusion admitted to KMCTH Dhital KR ${ }^{1}$, Acharya $\mathbf{R}^{1}$, Bhandari $\mathbf{R}^{1}$, Kharel $\mathbf{P}^{1}$, Giri KP², Tamrakar $\mathbf{R}^{3}$ \\ ${ }^{1}$ Interns, ${ }^{3}$ Lecturer, Department of Medicine, Kathmandu Medical College, Sinamangal, Nepal, ${ }^{2}$ Intern, B. P. Koirala Institute of Health Sciences, Dharan, Nepal
}

\begin{abstract}
Background: pleural effusion is the common findings in patients presenting with cardiopulmonary symptoms but specific studies are lacking in Nepal.

Objective: The main objective of this study is to find out the various causes of pleural effusion, their mode of clinical presentation and laboratory analysis of blood and pleural fluid to aid diagnosis of patients with pleural effusion.

Materials and methods: Retrospective data from July 2009 to July 2007 from all the cases diagnosed with pleural effusion were taken. Altogether 100 cases diagnosed with pleural effusion by chest X-ray (Posterior- Anterior and Lateral view) and Ultrasonogram of the chest were studied. The following parameters were analysed: Patients demographic profile, causes, location (Unilateral, Bilateral), Blood haemoglobin and count, sputum profile, Monteux test, chest Xray and USG findings and pleural fluid analysis[Biochemical, Haematological, Microbiological(culture and stain) and cytological]. This study was analysed by using SPSS 16.

Results: The mean age of the patient was $44.89 \pm 21.59$ and must patients with pleural effusion belong to age group $21-$ 30. Most common cause of pleural effusion was found to be tubercular effusion followed by parapneumonic effusion. Right sided effusion was seen in most cases of tubercular parapneumonic and malignant effusion whereas bilateral effusion was seen in $87.5 \%$ of the patient ( 7 out of 8 ) having congestive heart failure and all cases of renal disease (4 out of 4$)$. Shortness of breath (83\%), cough (67\%) and fever $(66 \%)$ are the most common mode of clinical presentation.

Conclusion: Our study concluded that the most common cause of unilateral pleural effusion is tuberculosis followed by parapneumonic effusion and most cases of those belong to younger age group (21 -30yrs) and most common cause of bilateral pleural effusion is congestive cardiac failure.
\end{abstract}

Key words: Pleural effusion, Tuberculosis, pneumonia, malignancy, protein, ADA

$\mathrm{P}^{\prime}$ leural effusion is a common finding among patients presenting with cardiopulmonary symptoms. A systemic approach to the investigations is needed because of the extensive differential diagnosis. Pleural effusions can be transudative or exudative ${ }^{1,2}$. In cases with transudative pleural effusion the diagnosis is usually made without much difficulties but exudative pleural effusion requires careful differential diagnosis that includes parapneumonic effusion, tuberculosis, and metastatic cancers which are found to be the cases in large number of patients $\mathrm{s}^{3-5}$.

Pleural effusion occurs when there is disequilibrium between the quantity of fluid entering and leaving the pleural space. Mechanisms by which the rate of fluid formation exceeds the rate of fluid absorption include increased pulmonary capillary pressure or permeability of the endothelial barrier, decreased intrapleural pressure or plasma oncotic pressure, obstructed lymphatic flow, diaphragmatic defects, and thoracic duct rupture ${ }^{6}$.

Tuberculosis is the most common cause of exudative pleural effusion in many areas of the world ${ }^{7,8}$. But in the developed world like United States, the leading etiologies of pleural effusion in adults who undergo thoracentesis are CHF, pneumonia, malignancy, pulmonary embolus, viral disease, coronary artery bypass surgery, and cirrhosis with ascites ${ }^{9}$.

The incidence of parapneumonic effusion among individuals with pneumonia ranges from $20 \%$ to $57 \%,{ }^{10-13}$ and the incidence of pleural effusions in decompensated congestive heart failure (CHF) may be as high as $87 \%{ }^{14}$.

Lung cancer is the most common metastatic tumours to the pleura in men and breast cancer in women. ${ }^{15}$ Together, both malignancies account for approximately $50-65 \%$ of all malignant effusions. Lymphoma, a tumour of the genitourinary tract and gastrointestinal tract, account for a further $25 \%$ of malignant effusions ${ }^{16-18}$. Pleural

Correspondence

Dr. Kamal Raj Dhital

Intern, Kathmandu Medical College Teaching Hospital,

Sinamangal, Kathmandu, Nepal

E-mail: kamaldhital@hotmail.com 
effusions from an unknown primary are responsible for $7-15 \%$ of all malignant pleural effusions ${ }^{19-21}$.

Even with this high risk of getting pleural effusion in so many different diseases, specific researches are lacking in studying these clinical spectrum in our country. This study gives the brief overview of clinical presentations and laboratory findings of all those patients admitted to Kathmandu Medical College Teaching Hospital (KMCTH) during the period of last 2 years which we hope will represent the clinical scenario in Nepal.

\section{Materials and methods}

This is a retrospective where data from all the cases diagnosed with pleural effusion in the medicine department of KMCTH from July 2007 to July 2009 were included. Data was taken from medical record section. Altogether 100 cases diagnosed with pleural effusion by chest x-ray (postero-anterior, anterioposterior and lateral view), and ultrasonogram were taken. Patients with diagnosis other than tubercular effusion, parapneumonic effusion, malignant effusion, congestive heart failure, due to liver disease and due to renal disease were mentioned as others. Patients demographics were enlisted alphabetically to avoid inclusion of same patient more than once. Any patients with confusion were deleted from the study. Results of this study was analysed by using SPSS software version 16 .

\section{Result}

All the cases with the diagnosis of pleural effusion admitted to medicine department of Kathmandu medical college teaching hospital, from July 2007 to July 2009 were included in the study.

The demographic profile of the patients studied is depicted in Table 1. Out of the total 100 cases, 48 were male and 52 female. Thus male to female ratio was 1:1.08. No obvious difference is observed between male and female in the study. 58 patients were from Kathmandu valley and others 42 were from outside Kathmandu valley. The age group was from above 14 years. The maximum number of patients with pleural effusion belonged to the age group 21-30 years and majority of cases of right sided pleural effusion were included in this age group. Among the various causes of pleural effusion the most common cause was tubercular type $(32 \%)$ followed by parapneumonic effusion $(30 \%)$. The third most common cause was due to malignancy $(18 \%)$ as shown in Table 2. Figure 1 shows the various age groups and the clinical diagnosis as shown in the diagram tubercular pleural effusion is common in the age group $21-30 y r s$.

Table 3 shows the various symptoms of the patients having pleural effusion. The most common mode of presentation of tubercular effusion and parapneumonic effusion was fever and shortness of breath where as in case of renal disease and liver disease common mode of presentation was generalized oedema. Fifty one patients $(51 \%)$ had right sided pleural effusion the most common cause of which was parapneumonic effusion followed by tubercular effusion. Thirty one patients (31\%) had left sided pleural effusion only most common cause of which was tubercular effusion followed by parapneumonic effusion. And eighteen patients (18\%) had bilateral pleural effusion most common cause of which was congestive cardiac failure. Shortness of breath was present in $83 \%$, cough in $67 \%$, fever in $66 \%$, chest pain in $40 \%$, oedema in $22 \%$, and haemoptysis in $16 \%$ and weight loss in $13 \%$. Out of 100 cases Monteux test was done for 72 patients among them only 17 patients $(23.6 \%)$ were positive and 55 patients were negative.

Out of 32 cases of tubercular pleural effusion 16 cases were found to be Monteux test positive.

In sputum cytology out of 18 cases of malignant effusion 7 cases shows malignant cells positive cytology. In sputum gram stain out of 89 cases of pleural effusion 24 cases shows gram stain positive. In sputum AFB staining 13 out of 89 cases were AFB stain positive, out of total positive cases 12 were tubercular effusion. Out of 88 cases of sputum culture only 10 are positive.

Figures 1, 2, 3 show the haematological, cytological and biochemical characteristic of the pleural fluids. Total count and differential count were done for 100 patients out of whom 61 had lymphocytes $>50 \%$ and only 39 patients had predominant polymorphonuclear cells. Patients with $\mathrm{CCF}$, malignant effusion, renal disease had low pleural fluid TC whereas patients with parapneumonic and tubercular effusion had raised pleural fluid total count.

PF protein level was determined in 100 patients. Mean protein level was $<3 \mathrm{gm} / \mathrm{dl}$ in patients with $\mathrm{CCF}$ and renal disease whereas $>3 \mathrm{gm} / \mathrm{dl}$ was observed in patients with tubercular, malignant, parapneumonic effusion.

LDH level was determined in 75 patients, mean level of LDH was: tubercular effusion (1359.38 U/L), parapneumonic effusion (1375.92 U/L) whereas in renal disease and liver disease the values were less than $200 \mathrm{U} / \mathrm{L}$

ADA level in pleural fluid was analyzed in 76 patients, only patient with tubercular pleural effusion show raised level of ADA ( $>60 \mathrm{U} / \mathrm{L})$. Mean value of ADA for tubercular effusion was $181.37 \mathrm{U} / \mathrm{L}$. 
Table 1: Demographic profile of the patients

\begin{tabular}{|l|c|}
\hline (1)Sex & Total Number \\
\hline Male & 48 \\
\hline Female & 52 \\
\hline (2)Address & \\
\hline Outside Kathmandu Valley & 42 \\
\hline Kathmandu Valley & 58 \\
\hline
\end{tabular}

Table 2: Diagnosis and number of cases

\begin{tabular}{|c|l|c|c|}
\hline S.N. & Diagnosis & Total Number & Percent (\%) \\
\hline 1 & Tubercular Effusion & 32 & 32 \\
\hline 2 & Parapneumonic Effusion & 30 & 30 \\
\hline 3 & Malignant Effusion & 18 & 8 \\
\hline 4 & Congestive Heart Failure & 8 & 4 \\
\hline 5 & Renal Disease & 4 & 3 \\
\hline 6 & Liver Disease & 3 & 5 \\
\hline 7 & Others & 5 & $\mathbf{1 0 0}$ \\
\hline & Total & $\mathbf{1 0 0}$ & \\
\hline
\end{tabular}

Table 3: Diagnosis and chief clinical mode of presentation

\begin{tabular}{|c|l|c|c|c|c|c|c|c|}
\hline S.N. & Diagnosis & $\begin{array}{c}\text { Shortness } \\
\text { of breath } \\
(\mathbf{\%})\end{array}$ & $\begin{array}{c}\text { Fever } \\
(\mathbf{\%})\end{array}$ & $\begin{array}{c}\text { Weight } \\
\text { loss } \mathbf{( \% )}\end{array}$ & $\begin{array}{c}\text { Oedema } \\
\mathbf{( \% )}\end{array}$ & $\begin{array}{c}\text { Haemoptysis } \\
\mathbf{( \% )}\end{array}$ & $\begin{array}{c}\text { Cough } \\
(\mathbf{\%})\end{array}$ & $\begin{array}{c}\text { Chest } \\
\text { pain } \\
(\%)\end{array}$ \\
\hline 1 & Tubercular effusion & 75 & 87.5 & 28.12 & 9.3 & 34.37 & 78.12 & 34.37 \\
\hline 2 & Parapneumonic effusion & 86.66 & 90 & 0 & 10 & 6.6 & 70 & 66.66 \\
\hline 3 & Malignant effusion & 94.94 & 33.33 & 22.22 & 16.66 & 66.66 & 66.66 & 38.88 \\
\hline 4 & Congestive cardiac failure & 87.5 & 12.5 & 0 & 62.5 & 0 & 57 & 0 \\
\hline 5 & Renal disease & 75 & 25 & 0 & 100 & 0 & 25 & 0 \\
\hline 6 & Liver disease & 66.66 & 66.66 & 0 & 100 & 0 & 0 & 0 \\
\hline 7 & Others & 80 & 20 & 0 & 20 & 0 & 80 & 40 \\
\hline
\end{tabular}

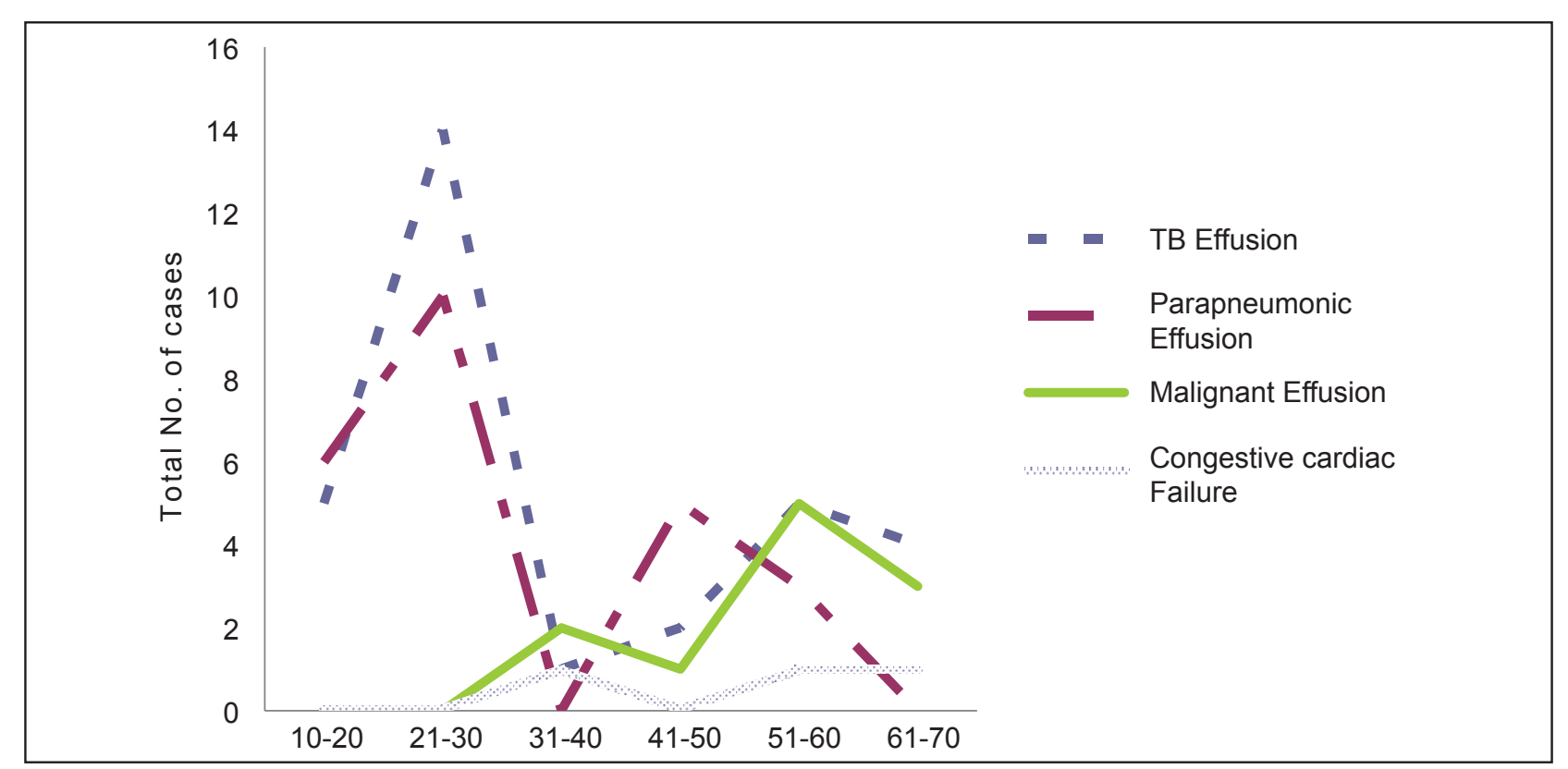

Fig 1: Age group and diagnosis 


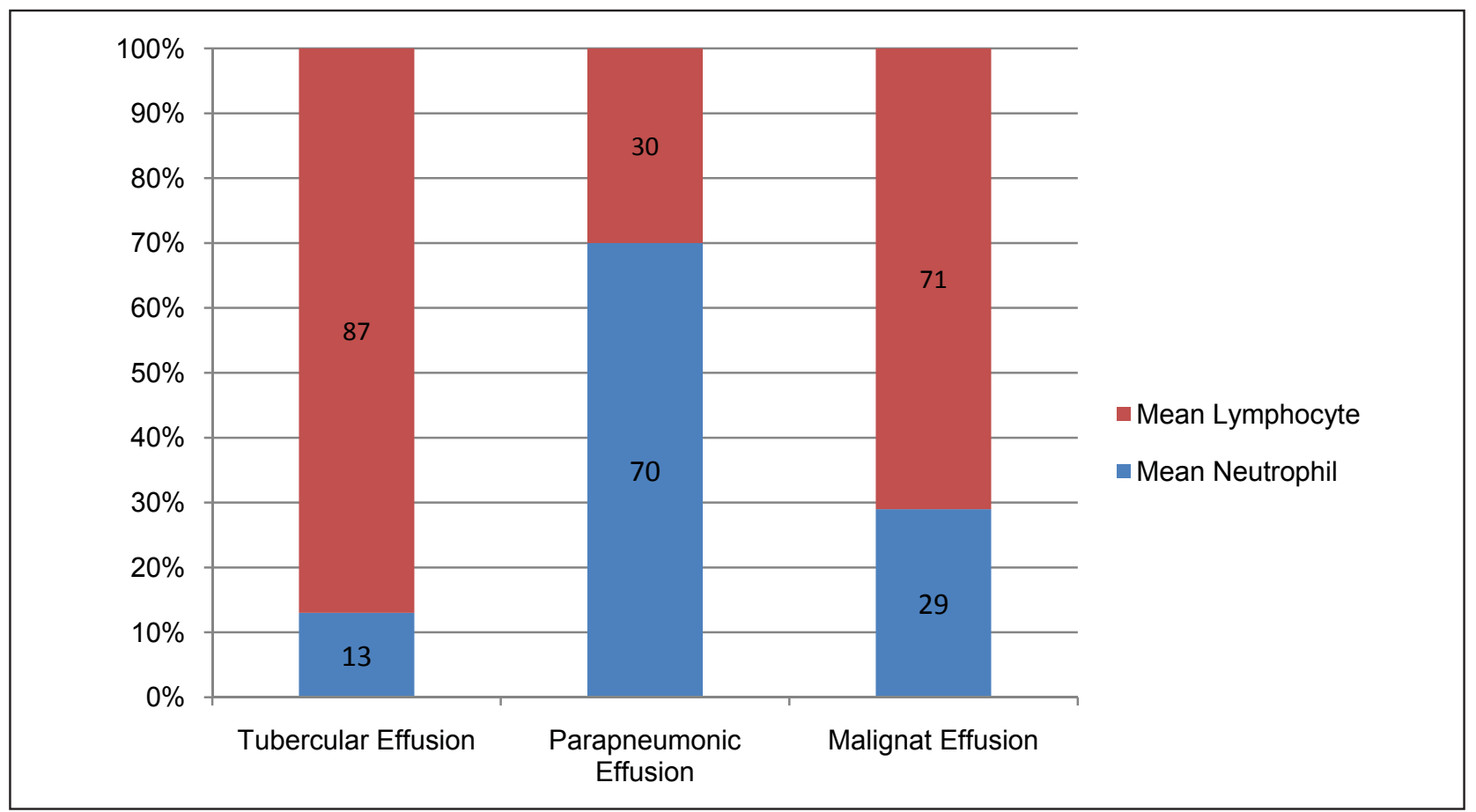

Fig 2: Diagnosis and mean lymphocyte and neutrophil count

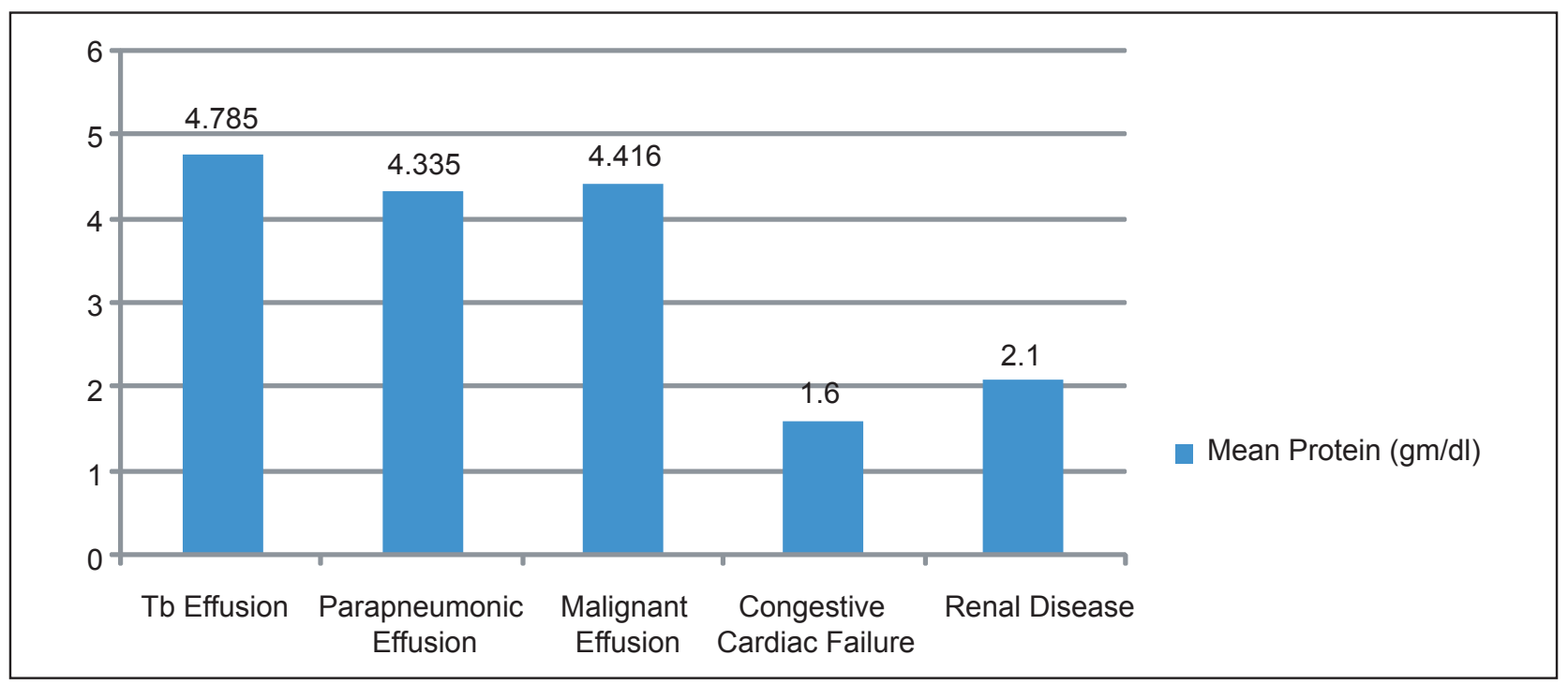

Fig 3: Diagnosis and mean protein level 


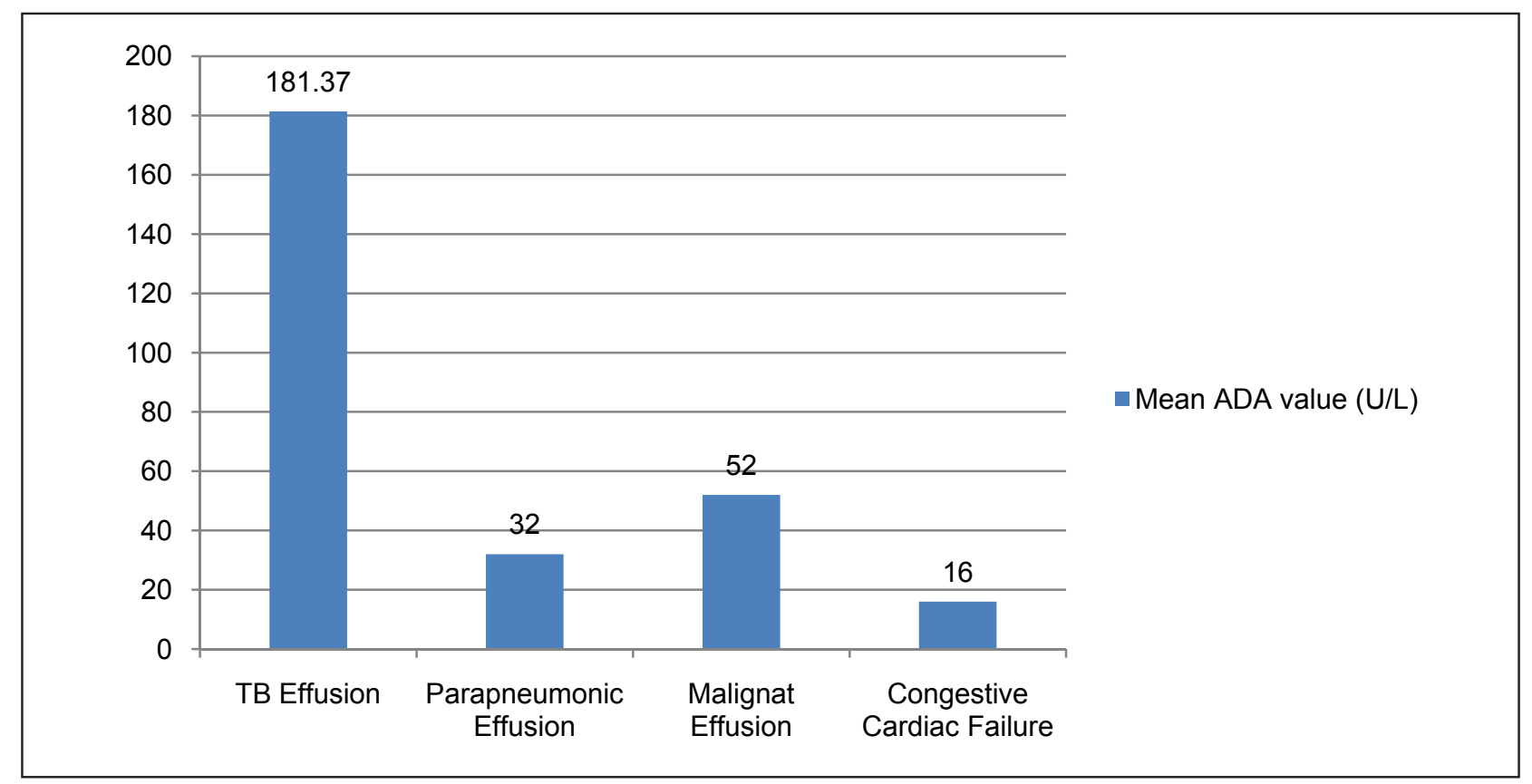

Fig 4: Diagnosis and mean ADA level

\section{Discussion}

Our study concludes that the tubercular effusion is the commonest cause of unilateral pleural effusion followed by parapneumonic effusion and congestive heart failure is the commonest cause of bilateral pleural effusion.

In developed countries as shown in study by Storey and coworkers $^{22}$ at mayo clinic in a series of 133 patients reported that malignancy accounted for nearly 50 percent of patients with pleural effusion and that nearly one third of the patients with malignancy and effusion had lymphoma. In contrast, less than 15 percent of the patients had the patients had heart failure.

Shortness of breath, fever and cough are the commonest mode of clinical presentation. Sputum profile (culture, Gram's stain, AFB stain and cytology) is not of much help in the work up of patient with pleural effusion. Pleural fluid analysis is the definite mode of separating transudative from exudative pleural analysis.

A systemic approach to the classification of pleural effusion is needed because of extensive differential diagnosis. Diagnostic exploration is based on the analysis of clinical variables (gender, age and symptoms), imaging (chest $\mathrm{x}$-ray, USG of chest) and laboratory analysis of blood and pleural fluid. Tubercular effusion is the common cause of exudative pleural effusion in many areas of the world ${ }^{7,8}$ which is consistent with our study which shows that 32 patients were having tubercular effusion out of 100. Tubercular effusion and parapneumonic effusion predominates among individuals younger than those with malignant effusion and congestive cardiac failure, a fact confirmed by in this study (total 62 patients belong to TB Effusion and parapneumonic effusion which predominate among 21 -30 age group).

A predominance of neutrophils in the pleural fluid (more than 50 percent of the cells) indicates that an acute process is affecting the pleura. In one series, 21 of 26 parapneumonic effusions (81 percent), 4 of 5 effusions secondary to pulmonary embolus ( 80 percent), and 4 of 5 effusions secondary to pancreatitis (80 percent) contained more than 50 percent neutrophils, but only 7 of 43 malignant effusions (16 percent) and none of 14 tuberculous effusions contained more than 50 percent neutrophils ${ }^{23}$. Our study also shows that in parapneumonic effusion mean total neutrophil is $70 \%$ which shows that parapneumonic effusion is an acute process affecting pleura where as predominance of mononuclear cells indicates a chronic process. A preponderance of small lymphocytes indicates that the patient most likely has cancer or tuberculous pleuritis, although such a preponderance is also seen in pleural effusions after coronary-artery bypass surgery ${ }^{23,24,25}$. The combined data from two series ${ }^{5,11}$ show that 90 of 96 exudative pleural effusions consisting of more than 50 percent lymphocytes ( 94 percent) were due to cancer or tuberculosis. In these series, 90 of 116 tuberculous pleural effusions (78 percent) contained more than 50 
percent lymphocytes. ${ }^{23,24}$ which is similar to that found in our study which showed that mean lymphocyte count was 87.61 and 70.74 percentage for tubercular effusion and malignant effusion respectively. Pleural fluid protein level is higher $>3 \mathrm{gm} / \mathrm{dl}$ among patients with exudative effusion like tubercular effusion and parapneumonic effusion where as it is low in transudative effusion like congestive cardiac failure, a fact confirmed by our study.

Several reports ${ }^{26}$ have suggested that an elevated pleural fluid ADA level predicts tuberculous pleuritis with a sensitivity of 90 to $100 \%$ and a specificity of 89 to $100 \%$. The reported cutoff value for ADA varies from 47 to $60 \mathrm{U} / \mathrm{L}^{25}$. In our lab Effusion is strongly suspected if pleural fluid ADA level is above $60 \mathrm{U} / \mathrm{L}$. mean value of ADA in tuberculous effusion is found $181.37 \mathrm{U} / \mathrm{L}$ in our study. However ADA may be falsely positive in few conditions $^{27-30}$. In our study also few cases of malignant pleural effusion had significant ADA level.

The level of lactate dehydrogenase in the pleural fluid correlates with the degree of pleural inflammation. ${ }^{31} \mathrm{In}$ our study, also raised level lo $\mathrm{LDH}$ was seen in inflammatory conditions like TB and Parapneumonic effusion and low in other conditions like congestive heart failure and liver disease.

As this is just the retrospective cross-sectional study, with small sample size, the findings should be interpreted with caution. However our study collaborates well with the other study and shows the various mode of clinical presentation, importance of sputum profile and pleural fluid analysis in patient presenting with pleural effusion. Further study would be required to determine the complete clinical profile patient presenting with pleural effusion in our setup.

\section{Conclusion}

Our study concluded that the most common cause of unilateral pleural effusion is tuberculosis followed by parapneumonic effusion and most cases of those belong to younger age group (21-30yrs) and most common cause of bilateral pleural effusion is congestive cardiac failure.

Our study concluded that shortness of breath, cough, and fever are the three most common mode of clinical presentation in patient with pleural effusion. Sputum profile does not help much in the workup of patient with pleural effusion. Pleural fluid analysis is the diagnostic method to distinguish exudative from transudative pleural effusion. Lymphocyte rich exudative effusion occurs in case of Tubercular effusion and neutrophil rich effusion occurs in parapneumonic effusion. Pleural fluid protein rises in patient with tubercular and parapneumonic effusion whereas its level decreasing in patient with liver disease and renal disease. High ADA concentration is highly sensitive diagnostic test in Tubercular effusion.

\section{Acknowledgement}

We would like to extent our heartiest gratitude to Mr. Subhash Chandra Sharma, Associate Professor, Department of Psychiatry, KMCTH and Mr. Buddha Shyam Sulu, Medical record division, KMCTH.

\section{References}

1. Chetty KG. Transudative pleural effusions. Clin Chest Med.1985; 6: 49-54.

2. Light RW. Diagnostic principles in pleural disease. Eur Respir J.1997; 10:476-81.

3. Storey DD, Dines DE, Coles DT. Pleural effusion: a diagnostic dilemma. Journal of the American Medical Association. 1976;236:2183-6.

4. Gannels JJ. Perplexing pleural effusion. Chest. 1978;47:390-3.

5. Keshmiri M,Hashemzadeh M.Use of cholesterol in differentiating of exudative and transudative pleural effusions. Medical journal of the Islamic Republic of Iran. 1997; 2(3):187-9.

6. Lai-Fook SJ. Pleural mechanics and fluid exchange. Physiol Rev. 2004; 84 (2):385-410.

7. Kalaajieh WK. Etiology of exudative pleural effusion in adults in north Lebanon. Canadian respiratory journal. 2001; 8(2):93-7.

8. Liam CK, Lim KH, Wong CM. Causes of pleural exudates in a region with a high incidence of tuberculosis. Respirology. 2000; 5:33-8.

9. Light RW. Clinical practice. pleural effusion. N Engl J Med. 2002;346(25):1971-7.

10. Bartlett JG, Finegold SM. Anaerobic infections of the lung and pleural space. Am Rev Respir Dis. 1974;110(1):56-77.

11. Fine NL, Smith LR, Sheedy PF. Frequency of pleural effusions in mycoplasma and viral pneumonias. N Engl J Med. 1970;283(15):790-3.

12. Light RW, Girard WM, Jenkinson SG, George RB. Parapneumonic effusions. Am J Med. 1980; 69(4):507-12.

13. Taryle DA, Potts DE, Sahn SA. The incidence and clinical correlates of parapneumonic effusions in pneumococcal pneumonia. Chest. 1978;74(2):17.

14. Kataoka H. Pericardial and pleural effusions in decompensated chronic heart failure. Am Heart J. 2000;139(5):918-23.

15. iBonito L, Falconieri G, Colautti I. The positive pleural effusion. A retrospective study 
of cytopathologic diagnoses with autopsy confirmation. Acta Cytol.1992;36:329-32.

16. Abbruzzese JL, Abbruzzese MC, Hess KR. Unknown primary carcinoma: natural history and prognostic factors in 657 consecutive patients. J Clin Oncol. 1994;12:1272-80.

17. Salyer WR, Eggleston JC, Erozan YS. Efficacy of pleural needle biopsy and pleural fluid cytopathology in the diagnosis of malignant neoplasm involving the pleura. Chest. 1975;67:536-9.

18. Hsu C. Cytologic detection of malignancy in pleural effusion: a review of 5255 samples from 3811 patients. Diagn Cytopathol. 1987;3:8-12.

19. Molengraft van de FJJM, Vooijs GP. Survival of patients with malignancy-associated effusions. Acta Cytol. 1989;33:911-6.

20. Salyer WR, Eggleston JC, Erozan YS. Efficacy of pleural needle biopsy and pleural fluid cytopathology in the diagnosis of malignant neoplasm involving the pleura. Chest. 1975;67:536-9.

21. Johnston WW. The malignant pleural effusion. A review of cytopathologic diagnoses of 584 specimens from 472 consecutive patients. Cancer. 1985;56:905-9.

22. Storey DD, Diners DE, Coles DT. Pleural effusion: a diagnostic dilemma. JAMA. 1976 ; 236 :2183-6.

23. Light RW, Erozan YS, Ball WC Jr. Cells in pleural fluid: their value in differential diagnosis. Arch Intern Med. 1973;132:854-60.
24. Yam LT. Diagnostic significance of lymphocytes in pleural effusions. Ann Intern Med. 1967;66:972-82.

25. Sadikot RT, Rogers JT, Cheng DS, Moyers P, Rodriguez M, Light RW. Pleural fluid characteristics of patients with symptomatic pleural effusion after coronary artery bypass graft surgery. Arch Intern Med.2000;160:26658.

26. Roth BJ. Searching for tuberculosis in the pleural space. Chest. 1999;116:3-5.

27. Light RW. Pleural diseases. 3rd edition. Baltimore: William \& Wilkins;1995 .p.154-66.

28. Kataria, YP, Khurshid I. Adenosine deaminase in the diagnosis of tuberculous pleural effusion. Chest. 2001;120:334-6.

29. Burgess, LJ, Maritz, FJ, Le Roux, I. Combined use of pleural adenosine deaminase with lymphocyte/neutrophil ratio: increased specificity for the diagnosis of tuberculous pleuritis. Chest. 1996;109,414-9.

30. Riantawan $\mathrm{P}$, Chaowalit $\mathrm{P}$, Wongsangiem $\mathrm{M}$. Diagnostic value of pleural fluid adenosine deaminase in tuberculous pleuritis with reference to HIV coinfection and a Bayesian analysis. Chest. 1999;116,97-103.

31. Light RW. Pleural diseases. 4th edition. Philadelphia: Lippincott Williams \& Wilkins, 2001. 